ARTICLE

DOI: $10.1038 / \mathrm{s} 41467-018-03700-3$

\title{
Extraordinary pseudocapacitive energy storage triggered by phase transformation in hierarchical vanadium oxides
}

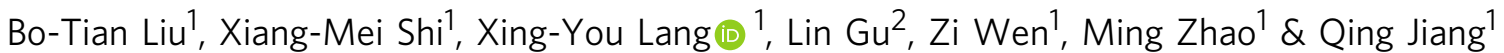

\begin{abstract}
Pseudocapacitance holds great promise for improving energy densities of electrochemical supercapacitors, but state-of-the-art pseudocapacitive materials show capacitances far below their theoretical values and deliver much lower levels of electrical power than carbon-based materials due to poor cation accessibility and/or long-range electron transferability. Here we show that in situ corundum-to-rutile phase transformation in electron-correlated vanadium sesquioxide can yield nonstoichiometric rutile vanadium dioxide layers that are composed of highly sodium ion accessible oxygen-deficiency quasi-hexagonal tunnels sandwiched between conductive rutile slabs. This unique structure serves to boost redox and intercalation kinetics for extraordinary pseudocapacitive energy storage in hierarchical isomeric vanadium oxides, leading to a high specific capacitance of $\sim 1856 \mathrm{~F} \mathrm{~g}^{-1}$ (almost sixfold that of the pristine vanadium sesquioxide and dioxide) and a bipolar charge/discharge capability at ultrafast rates in aqueous electrolyte. Symmetric wide voltage window pseudocapacitors of vanadium oxides deliver a power density of $\sim 280 \mathrm{~W} \mathrm{~cm}^{-3}$ together with an exceptionally high volumetric energy density of $\sim 110 \mathrm{mWh} \mathrm{cm}^{-3}$ as well as long-term cycling stability.
\end{abstract}

\footnotetext{
${ }^{1}$ Key Laboratory of Automobile Materials (Jilin University), Ministry of Education, and School of Materials Science and Engineering, Jilin University, Changchun 130022, China. ${ }^{2}$ Beijing National Laboratory for Condensed Matter Physics, The Institute of Physics, Chinese Academy of Sciences, Beijing 100190, China. These authors contributed equally: Bo-Tian Liu, Xiang-Mei Shi. Correspondence and requests for materials should be addressed to X.-Y.L. (email: xylang@jlu.edu.cn) or to Q.J. (email: jiangq@jlu.edu.cn)
} 
T ransition-metal oxides (TMOs) are attractive pseudocapacitive materials in electrochemical supercapacitors because they have theoretical-specific capacitance more than one or two orders of magnitude higher than that of carbon-based materials $\left(\sim 5-15 \mu \mathrm{F} \mathrm{cm}^{-2}\right)^{1-3}$. Unlike carbon materials in which only electric double-layer capacitance is available $^{1-6}$, pseudocapacitive TMOs store/release charges by cation adsorption/desorption (redox pseudocapacitance) $)^{7-9}$ or/and intercalation/de-intercalation (intercalation pseudocapacitance) $)^{10-13}$ coupled with reversible redox reactions of metal ions at or near the electrode/electrolyte interface. Both faradaic mechanisms can work separately or together, depending on the crystallographic structures of the electroactive materials whether they localize the redox reactions on the surface or accommodate cations in the interlayer gaps or tunnels $2,14,15$. However, no matter which type of pseudocapacitive mechanisms is mainly involved in the charge storage/delivery, the electroactive TMOs are required to play dual roles during the charge/ discharge processes, i.e., accommodating cations at the surface or in the interlayer gaps, and transferring the generated electrons from the redox sites to the conductive materials ${ }^{16}$. The tradeoff between cation accessibility/diffusion and electronic conductivity in state-of-the-art TMOs makes them difficult to really realize the energy storage with battery-like capacity and carbon-based supercapacitors-like rate performance. For instance, the redox pseudocapacitive TMOs (such as $\mathrm{RuO}_{2}{ }^{17,18}$ and $\mathrm{MnO}_{2}{ }^{19-21}$ ) often have too small interlayer gaps to accommodate cation insertion/extraction, which essentially localizes the redox reaction of metal ions at the surface of electroactive materials on the time scale of interest ${ }^{21,22}$; while the ones with facile cation accessibility and diffusion (such as layered $\mathrm{Nb}_{2} \mathrm{O}_{5}{ }^{11}, \mathrm{MnO}_{2}{ }^{22}$ and $\mathrm{MoO}_{3}{ }^{23}$ ) generally suffer from poor electronic conductivity $11,15,16,21-24$, which significantly impedes the long-range transfer of electrons from the surface redox sites to current collectors. Consequently, they usually achieve practical capacitances far below their theoretical expectations and deliver much lower levels of electrical power than carbon materials, unsatisfying the fast-growing demands of high-power and high-energy densities in portable electronic devices and hybrid vehicles with limited area and volume.

Here we report a class of bipolar TMOs, of which the crystallographic structures are designed and regulated to facilitate simultaneously cation accessibility/diffusion and electron transfer, for realizing high levels of energy storage at fast charge/discharge rates in symmetric aqueous pseudocapacitors with a wide voltage window. Specifically, vacancyordered rutile $\mathrm{VO}_{2-x}$ phases $\left(r-\mathrm{VO}_{2-x}\right)$, which are composed of highly cation accessible hexagonal oxygen-deficiency tunnels and conductive $r-\mathrm{VO}_{2}(x=0)$ slabs, are in situ produced and seamlessly integrated with the precursor corundum $\mathrm{V}_{2} \mathrm{O}_{3}\left(c-\mathrm{V}_{2} \mathrm{O}_{3}\right)$ core in a hierarchically nanoporous architecture (NP $c-\mathrm{V}_{2} \mathrm{O}_{3} / r-\mathrm{VO}_{2-x}$ ) by a thermal-oxidation-triggered corundum-to-rutile (CTR)-phase transformation. As a result of offering both intercalation and redox pseudocapacitance with similarly facile kinetics and shortening electron transfer distance from the redox sites to conductive intermediate via metallic $\mathrm{V}-\mathrm{V}$ chains, the $\mathrm{NP} c-\mathrm{V}_{2} \mathrm{O}_{3} / r-\mathrm{VO}_{2-x}$ hybrid electrodes exhibit about six times the specific and volumetric pseudocapacitance of $\mathrm{NP} r-\mathrm{VO}_{2}\left(\sim 1856 \mathrm{~F} \mathrm{~g}^{-1}\right.$ and $\left.\sim 1933 \mathrm{~F} \mathrm{~cm}^{-3}\right)$ with exceptionally high-rate performance. This enlists their aqueous pseudocapacitors to have a volumetric energy of $\sim 330$ $\mathrm{mWh} \mathrm{cm}{ }^{-3}\left(\sim 13 \mathrm{mWh} \mathrm{cm}^{-3}\right.$ based on the whole volume of device, comparable to that of $4 \mathrm{~V} / 500 \mu \mathrm{Ah}$ thin-film lithium batteries) at high levels of power delivery similar to carbon-based supercapacitors.

\section{Results}

DFT simulation. Both vanadium sesquioxide and dioxide are archetypal electron-correlated materials with metal-toinsulator transitions (MITs) ${ }^{25}, 26$, through which their hightemperature phases, i.e., $c-\mathrm{V}_{2} \mathrm{O}_{3}$ and $r-\mathrm{VO}_{2}$ (Supplementary Figure $1 \mathrm{a}, \mathrm{b})$, are conductive in virtue of the itinerant $3 d^{2}$ $\left(\mathrm{V}^{3+}\right)$ and $3 d^{1}\left(\mathrm{~V}^{4+}\right)$ electrons along short $\mathrm{V}-\mathrm{V}$ chains, respectively. As illustrated by typical temperature-resistivity curves for $\mathrm{V}_{2} \mathrm{O}_{3}$ and $\mathrm{VO}_{2}$ films deposited on $\mathrm{Al}_{2} \mathrm{O}_{3}$ substrates, their electronic conductivity reaches $\sim 10^{3}-10^{4} \mathrm{~s} \mathrm{~cm}^{-1}$ at room temperature by virtue of metallization via MITs (Supplementary Figure 1c). Distinguished from the rhombohedral $c-\mathrm{V}_{2} \mathrm{O}_{3}$ with the tetrahedral interstices that are too small to assist $\mathrm{Na}$ ion diffusion ${ }^{27,28}$, the $r$ - $\mathrm{VO}_{2}$ has a tunnel structure, in which both cations and electrons prefer to transport along the $z$-axis tunnels and the shortly $\mathrm{V}-\mathrm{V}$ bonded walls, respectively $27,29,30$. These distinct properties imply their favorable

roles in electrochemical energy storage: the former serving as the conductor to facilitate electron transport along a three-dimensional (3D) vanadium-atom framework and the latter accommodating cation storage in the tunnels as the electroactive intermediate. Nevertheless, the pristine $r-\mathrm{VO}_{2}$ with [1×1] tunnels exhibits unexpectedly low capacitance because of unnegligible oscillation of electrostatic potential near the surface 31 , which dramatically increases the initial energy barrier and thus confines the redox reaction at the electrode/ electrolyte interface ${ }^{31,32}$. Using density functional theory (DFT) calculations, we demonstrate that the CTR-phase transformation in oxygen nonstoichiometry produces the $r$ - $\mathrm{VO}_{2-x}$ phase to grow epitaxially on the precursor $c-\mathrm{V}_{2} \mathrm{O}_{3}$ substrate on account of the compressive strain at their interface (Fig. 1a and Supplementary Figure 2). This metastable rutile phase consists of quasihexagonal tunnels with a cross-section area of $\sim 24 \AA^{2}$ alternatingly sandwiched between rutile slabs with thicknesses of unit cells (Fig. $1 \mathrm{~b}$ and Supplementary Figure 3). Therein, $\mathrm{Na}$ ions tend to be levitated at the tunnel center with the intercalation energy $\left(E_{\text {int }}\right)$ of about $-0.8 \mathrm{eV}$ and transport along the tunnels with a low energy barrier $\left(E_{\mathrm{b}}\right)$ of $\sim 0.02 \mathrm{eV}$ because of their analogous interactions with the surrounding oxygen atoms (Supplementary Figure 4a), in sharp contrast to those in the pristine $r-\mathrm{VO}_{2}$ with $E_{\text {int }}=\sim 0.9 \mathrm{eV}$ and $E_{\mathrm{b}}=\sim 0.1 \mathrm{eV}$ (Fig. 1c, d). Meanwhile, not only the rutile slabs but also the walls of quasi-hexagonal tunnels remain high electronic conductivity, which enables electron transfer in the atomic distance from the redox sites to the conductive $\mathrm{V}-\mathrm{V}$ chains ${ }^{27,}{ }^{29}$ (Fig. 1e). As shown in the typical V-V chains along $z$-axis (Fig. 1f, g), the oxygen nonstoichiometry results in evident orbital overlapping between the nearest neighbor $\mathrm{V}$ atoms, where the charge densities associated with states close to Fermi level are calculated according to the density of states ranging from $E_{\mathrm{F}}-0.8$ to $E_{\mathrm{F}}+0.8 \mathrm{eV}$ (Supplementary Figure $4 \mathrm{~b}$ ). The increase of rutile slab thickness does not give rise to remarkable changes of electron and ion transport kinetics except for the influence on the capacitance of $r$ - $\mathrm{VO}_{2-x}$ (Fig. 1c, d), in which the quasi-hexagonal tunnels accommodate $\mathrm{Na}^{+}$ions to offer intercalation pseudocapacitance $\left(C_{\mathrm{v}, \text { int }}\right)$ and the $r-\mathrm{VO}_{2}$ slabs localize the redox reaction on the surface for the redox pseudocapacitance $\left(C_{\mathrm{s}, \mathrm{VO} 2}\right)$. As shown in the phase diagram for specific capacitance versus $x$ value (Supplementary Figure 5), the $r$ - $\mathrm{VO}_{2-x}$ is predicted to exhibit a linearly increasing specific capacitance with the increasing $x$ value and reach the theoretical value $\left(2292 \mathrm{~F} \mathrm{~g}^{-1}\right)$ at $x=1 / 4$ according to the equation, $C_{\mathrm{s}}=$ $\left[4 x C_{\mathrm{v}, \text { int }}+(1-4 x) C_{\mathrm{s}-\mathrm{VO} 2}\right]$. As the $x$ value further increases, there forms a mixture of $r-\mathrm{VO}_{2-x}$ and $c-\mathrm{V}_{2} \mathrm{O}_{3}$ with the decreasing specific capacitance, which is determined in terms of 
a

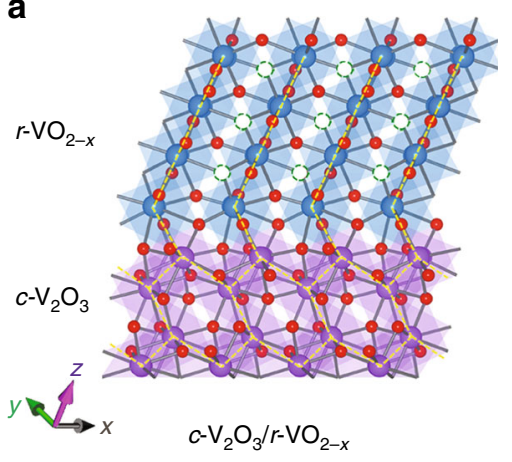

b

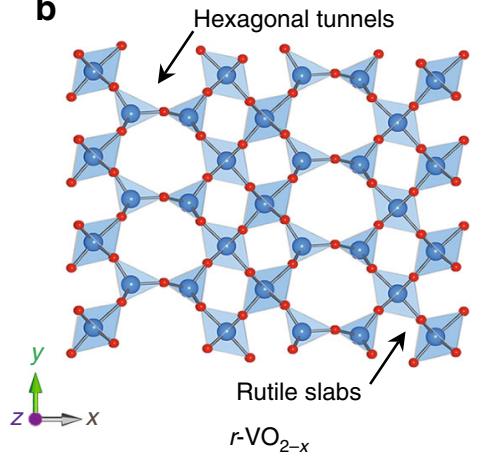

c

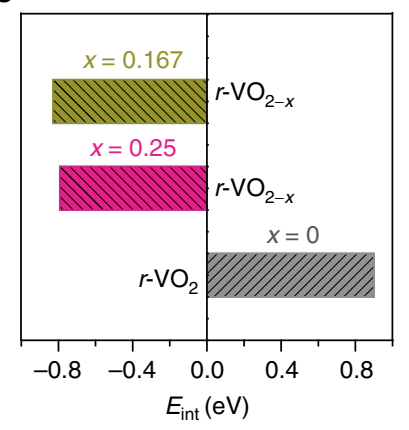

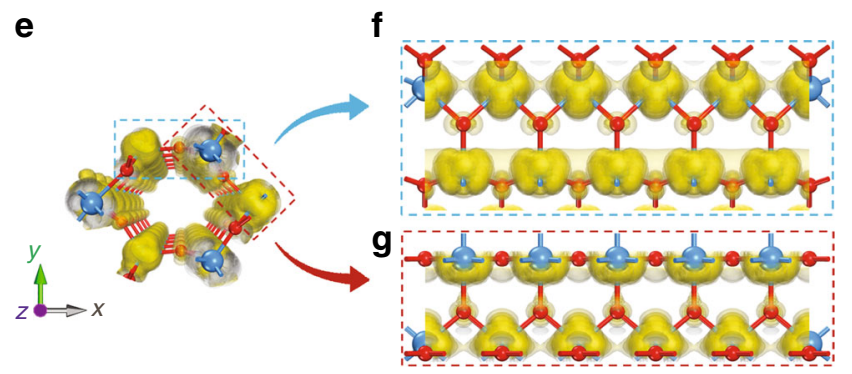

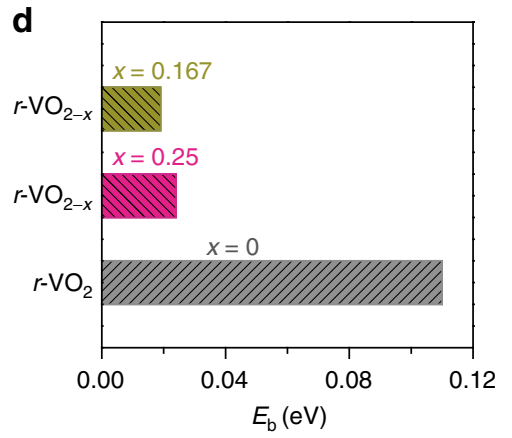

Fig. 1 Structures and DFT computations of vanadium oxides with high electronic conductivity and ionic accessibility. a Atomic schematic illustration for the isomeric vanadium oxides produced by in situ corundum-to-rutile-phase transformation, which consist of corundum-type $\mathrm{V}_{2} \mathrm{O}_{3}$ and rutile $r$ - $\mathrm{VO}_{2-x}$ core/ shell structure. Yellow dashed lines denote the electron transport pathways along short $\mathrm{V}-\mathrm{V}$ bonds. Purple and blue balls represent vanadium atoms in corundum-type $\mathrm{V}_{2} \mathrm{O}_{3}$ and rutile-type $\mathrm{VO}_{2-x}$, red and white ones denote oxygen atoms and ordered oxygen vacancies. b Representative atomic structure of the $r$ - $\mathrm{VO}_{2-x}$ layer with ordered 1D quasi-hexagonal tunnels along z-axis. c, $\mathbf{d}$ Comparison of intercalation energy $\left(E_{\text {int }}\right)(\mathbf{c})$ and energy barrier $\left(E_{\mathrm{b}}\right)(\mathbf{d})$ for $\mathrm{Na}$ + in the tunnels of the $r-\mathrm{VO}_{2}$ and $r-\mathrm{VO}_{2-x}$ with $x=0.25$ and 0.167 . e-g Electron density distributions of the projected orbitals for the quasi-hexagonal tunnel (e) and the $\mathrm{V}-\mathrm{O}$ walls of quasi-hexagonal tunnel (f) and rutile slab ( $(\mathbf{g})$

$C_{\mathrm{s}}=\left\{4(0.5-x) C_{\mathrm{v}, \text { int }}+[1-4(0.5-x)] C_{\mathrm{s}, \mathrm{V} 2 \mathrm{O} 3}\right\}$. Here $C_{\mathrm{s}, \mathrm{V} 2 \mathrm{O} 3}$ is the redox pseudocapacitance of $c-\mathrm{V}_{2} \mathrm{O}_{3}$.

Synthesis and characterizations. To extend the DFT predictions to designing practical electrodes, the $\mathrm{NP} c-\mathrm{V}_{2} \mathrm{O}_{3} / r-\mathrm{VO}_{2-x}$ hybrids are fabricated by a facile thermal oxidation of $c-\mathrm{V}_{2} \mathrm{O}_{3}$ precursor skeletons under the short supply of oxygen (Fig. 2a). Therein, the in situ CTR-phase transformation is triggered to produce the $r$ $\mathrm{VO}_{2-x}$ layers (Fig. $2 \mathrm{~b}$ ), which evolve with the thermal-oxidation time. Figure $2 \mathrm{c}$ and Supplementary Figure 6a show typical scanning electron microscope (SEM) images of $\mathrm{NP} c-\mathrm{V}_{2} \mathrm{O}_{3} / r-\mathrm{VO}_{2}$ ${ }_{-x}$ film electrodes with thickness of $\sim 1.2 \mu \mathrm{m}$ (thermal oxidation, $10 \mathrm{~min}$ ), displaying the same 3D bicontinuous nanoporous structure as that of the NP $c-\mathrm{V}_{2} \mathrm{O}_{3}$ skeleton which consists of periodic walls and multimodal open nanopores. In addition to the ordered macropores with sizes of $360 \mathrm{~nm}$ and $\sim 100 \mathrm{~nm}$ based on opal template, there are abundant mesopores and micropores to be directly observed in the transmission electron microscope (TEM) images of $\mathrm{NP} c-\mathrm{V}_{2} \mathrm{O}_{3} / r-\mathrm{VO}_{2-x}$ walls (Fig. $2 \mathrm{~d}$ and Supplementary Figure $6 \mathrm{~b}, \mathrm{c}$ ). The multimodal feature is confirmed by a type IV nitrogen adsorption/desorption isotherm (Supplementary Figure 6d), which signifies a mesopore size distribution with distinct maxima centered at $\sim 4 \mathrm{~nm}, \sim 10 \mathrm{~nm}$ and $\sim 70 \mathrm{~nm}$ (Supplementary Figure 6e). The ultrasmall pores in the $\mathrm{NP} c-\mathrm{V}_{2} \mathrm{O}_{3} / r$ $\mathrm{VO}_{2-x}$ film electrodes are responsible for the Brunauer-Emmett-Teller (BET) surface areas of as high as $\sim 99.8$ $\mathrm{m}^{2} \mathrm{~g}^{-1}$, and the large pores provide electrolyte channels to enhance ion transport properties. During the CTR-phase transformation, the shearing movement of $\mathrm{V}$ atoms in the $c-\mathrm{V}_{2} \mathrm{O}_{3}(012)$ basal plane along [121] direction gives rise to the formation of $r$ -
$\mathrm{VO}_{2}(011)$ planes but with a mismatch of $8.08 \%$ along the [100] direction $^{33}, 34$ (Supplementary Figures 2a and 7). Such large compressive strain makes it thermodynamically favorable to form ordered oxygen vacancies, i.e., the quasi-hexagonal tunnels in the $r-\mathrm{VO}_{2-x}$ phases, for lowering elastic energy (Supplementary Figure 7) when they are epitaxially growing on the $c-\mathrm{V}_{2} \mathrm{O}_{3}$ skeleton along the [001] direction (Supplementary Figure 2b, c). This is verified by a compelling evidence demonstrated by highresolution transmission electron microscope (HR-TEM) and aberration-corrected high-angle annular dark-field (HAADF) scanning TEM (HAADF-STEM). As shown in representative HRTEM images of $c-\mathrm{V}_{2} \mathrm{O}_{3} / r-\mathrm{VO}_{2-x}$ (Fig. 2e), the metastable $r$ - $\mathrm{VO}_{2}$ ${ }_{-x}(\overline{1} 01)$ layer is seamlessly integrated with the $c-\mathrm{V}_{2} \mathrm{O}_{3}(110)$ core skeletons via short V-V bonds (Fig. 2f and Supplementary Figure 2d). Viewed along the [001] axis, the structure composed of alternating quasi-hexagonal tunnels and rutile slabs with $[1 \times 1]$ tunnels is directly observed from atomic-resolution HAADFSTEM image (Fig. 2g), wherein the atoms sitting inside the hexagonal tunnels are attributed to the $\mathrm{V}$ atoms in the $\mathrm{V}_{2} \mathrm{O}_{3}$ substrate. Further image simulations confirm that bright spots correspond to atomic columns, among which the dark hexagons and squares are due to the quasi-hexagonal tunnels and [1×1] tunnels in the rutile slabs, respectively (Fig. $2 \mathrm{~h}$ ). A typical line profile demonstrates a large and aperiodic fluctuation around $\sim 1$ $\mathrm{nm}$ to validate the quasi-hexagonal tunnel that is produced in the CTR transformation via shearing movement (Fig. 2i).

Such CTR-phase transformation process is also attested by Xray diffraction (XRD) patterns (Fig. 3a) and Raman spectra (Supplementary Figure 8a) for the $\mathrm{NP} c-\mathrm{V}_{2} \mathrm{O}_{3} / r-\mathrm{VO}_{2-x}$ films, of which the characteristic peaks match well with those of the pristine NP $c-\mathrm{V}_{2} \mathrm{O}_{3}$ and $r-\mathrm{VO}_{2}$ films. As shown in the XRD 
a

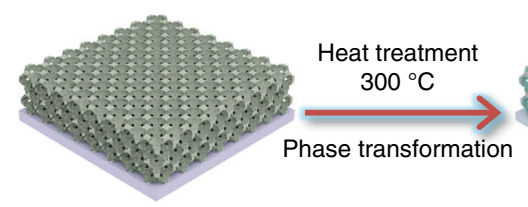

$c-\mathrm{V}_{2} \mathrm{O}_{3}$
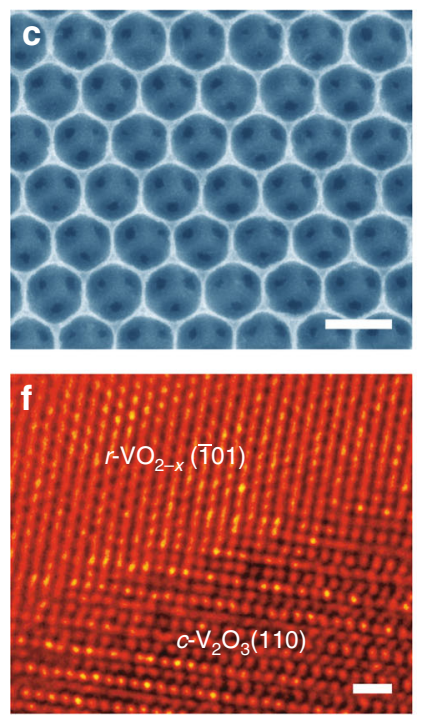

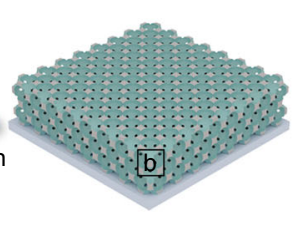

$r-\mathrm{VO}_{2-x}$
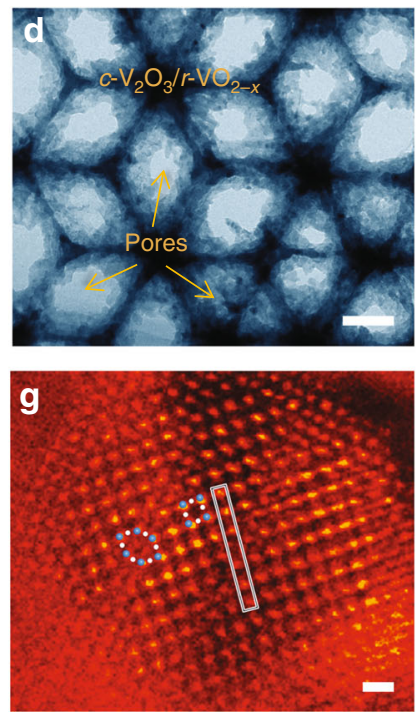

b
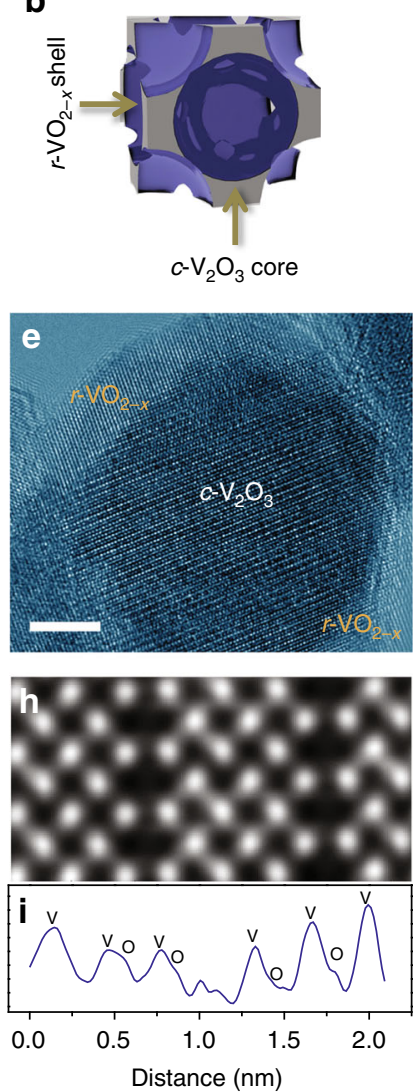

Fig. 2 Preparation and structural characterization of isomeric vanadium oxides. a Scheme for in situ corundum-to-rutile-phase transformation triggered by thermal oxidation to fabricate hierarchical nanoporous isomeric $c-\mathrm{V}_{2} \mathrm{O}_{3} / r-\mathrm{VO}_{2-x}$ from precursor $3 \mathrm{D} \mathrm{V}_{2} \mathrm{O}_{3}$ skeleton. $\mathbf{b}$ Core/shell structure of isomeric of $c$ $\mathrm{V}_{2} \mathrm{O}_{3} / r-\mathrm{VO}_{2-x}$. c SEM image of nanoporous $c-\mathrm{V}_{2} \mathrm{O}_{3} / r-\mathrm{VO}_{2-x}$ films with an ordered macroporous structure. Scale bar, $500 \mathrm{~nm}$. d-f Bright-field TEM and HR-TEM images of $c-V_{2} \mathrm{O}_{3} / r-\mathrm{VO}_{2-x}$ core/shell structure (d, e) and epitaxially interfacial structure (f). Scale bar, $100 \mathrm{~nm}(\mathbf{d}), 5 \mathrm{~nm}(\mathbf{e})$ and $1 \mathrm{~nm}(\mathbf{f})$. $\mathbf{g}$ HAADF-STEM image of the $r$ - $\mathrm{VO}_{2-x}$ layer viewed from the [001] axis, demonstrating an alternating structure of quasi-hexagonal tunnels and rutile slabs. Scale bar, $0.5 \mathrm{~nm}$. $\mathbf{h}$ Simulated HAADF-STEM image of quasi-hexagonal tunnel structure in $(\mathbf{g})$. $\mathbf{i}$ Line profile of column of atoms in the white boxed area

pattern of the NP $c-\mathrm{V}_{2} \mathrm{O}_{3} / r-\mathrm{VO}_{2-x}$ film (thermal oxidation, 10 $\mathrm{min})$, the diffraction peaks correspond to the (110), (011), (111), (120), (121), (220) and (130) planes of the rutile phase in space group $\mathrm{P}_{2} / \mathrm{mnm}$ (JCPDS 44-0253), apart from ones attributed to the precursor $c-\mathrm{V}_{2} \mathrm{O}_{3}$ (JCPDS 34-0187). These characteristic peaks of the $r-\mathrm{VO}_{2-x}$ gradually intensify with the thermaloxidation time from 10 to $60 \mathrm{~min}$, indicating the increase of rutile-phase volume fraction. While extending the thermaloxidation time to $90 \mathrm{~min}$, the $\mathrm{NP} c-\mathrm{V}_{2} \mathrm{O}_{3}$ is completely transformed into the $\mathrm{NP} r-\mathrm{VO}_{2}$ (Fig. $3 \mathrm{a}$ and Supplementary Figure 8a). The evolution of chemical state of $\mathrm{V}$ atoms in the $r$ $\mathrm{VO}_{2-x}$ layer during the CTR-phase transformation is identified by X-ray photoelectron spectroscopy (XPS). Compared with the XPS spectrum of the NP $c-\mathrm{V}_{2} \mathrm{O}_{3}$ film mainly containing $\mathrm{V}^{3+}$ (Fig. 3b), there are only V $2 p_{3 / 2}(516.6 \mathrm{eV})$ and $\mathrm{V} 2 p_{1 / 2}(524.1 \mathrm{eV})$ peaks corresponding to $\mathrm{V}^{4+}$ in the $\mathrm{NP} r-\mathrm{VO}_{2}$ (Fig. $\left.3 \mathrm{~d}\right)^{35}$. While in the XPS spectra of the NP $c-\mathrm{V}_{2} \mathrm{O}_{3} / r-\mathrm{VO}_{2-x}$ films, the $\mathrm{V} 2 p_{3 / 2}$ and $\mathrm{V} 2 p_{1 / 2}$ signals are deconvolated into two more peaks at the binding energies of 515.5 and $522.8 \mathrm{eV}$ due to the presence of $\mathrm{V}^{3}$ ${ }^{+}$in the quasi-hexagonal tunnels ${ }^{35}$, in addition to those of $\mathrm{V}^{4+}$ in the rutile slabs (Fig. 3c and Supplementary Figure 9). According to the intensity ratio of $\mathrm{V}^{3+} / \mathrm{V}^{4+}$ at the $\mathrm{V} 2 p_{3 / 2}$ peaks, the $x$ value in the $r-\mathrm{VO}_{2-x}$ is determined to be in the range from 0.22 to 0.1 with the thermal-oxidation time (Supplementary Figure 10). Such high density of quasi-hexagonal tunnels in the $r$ - $\mathrm{VO}_{2-x}$ layer not only ameliorates the cation accessibility but also stabilizes the conductive rutile phases at room temperature by shifting the MIT temperature down to $\sim 180 \mathrm{~K}$ (Supplementary Figure 1c) ${ }^{26}$. In particular, almost all the $\mathrm{V}-\mathrm{V}$ bonds at their interfaces is shorter than the critical separation value of the $3 d$ electron coupling interaction $(0.293 \mathrm{~nm})$ (Supplementary Figure 11$)^{27}$, which serve as the electron transport pathways between $\mathrm{V}_{2} \mathrm{O}_{3}$ and $r-\mathrm{VO}_{2-x}$ without any additional contact resistance. As illustrated by the current-voltage $(I-V)$ measurement on the NP $c-\mathrm{V}_{2} \mathrm{O}_{3} / r-\mathrm{VO}_{2-x}$ film $(x=0.22)$, the $I-V$ curve in the range of -0.8 to $0.8 \mathrm{~V}$ is linear (Fig. 3e), with a resistance of $\sim 17 \Omega$, only slightly higher than that of the pristine NP $c-\mathrm{V}_{2} \mathrm{O}_{3}(\sim 14 \Omega)$ (inset of Fig. 3e).

Electrochemical characterizations. The electrochemical properties of nanoporous vanadium oxide electrodes are measured in a three-electrode configuration using a Pt foil as the counter electrode and a $\mathrm{Ag} / \mathrm{AgCl}$ electrode as reference electrode. Figure $4 \mathrm{a}$ shows typical cyclic voltammograms (CVs) for the $\mathrm{NP} c-\mathrm{V}_{2} \mathrm{O}_{3} / r$ $\mathrm{VO}_{2-x}(x=0.22), c-\mathrm{V}_{2} \mathrm{O}_{3}$ and $r-\mathrm{VO}_{2}$ electrodes in $1 \mathrm{M} \mathrm{Na} \mathrm{SO}_{4}$ aqueous electrolyte at a scan rate of $50 \mathrm{mV} \mathrm{s}^{-1}$, exhibiting a quasirectangular shape in a potential window of 0 to $0.8 \mathrm{~V}$. In virtue of the 3D hierarchical and bicontinuous nanoporous architecture which simultaneously provides high electron and ion transport pathways, their CV curves at various scan rates from 5 to 1000 $\mathrm{mV} \mathrm{s}^{-1}$ retain a quasi-rectangular shape, indicating their extraordinary high-rate performance (Supplementary Figure 12a,b,c). Relative to the NP $c-\mathrm{V}_{2} \mathrm{O}_{3}$ and $r$ - $\mathrm{VO}_{2}$ electrodes, the NP $c-\mathrm{V}_{2} \mathrm{O}_{3}$ l $r-\mathrm{VO}_{2-x}$ hybrid electrode has remarkably enhanced current 
a

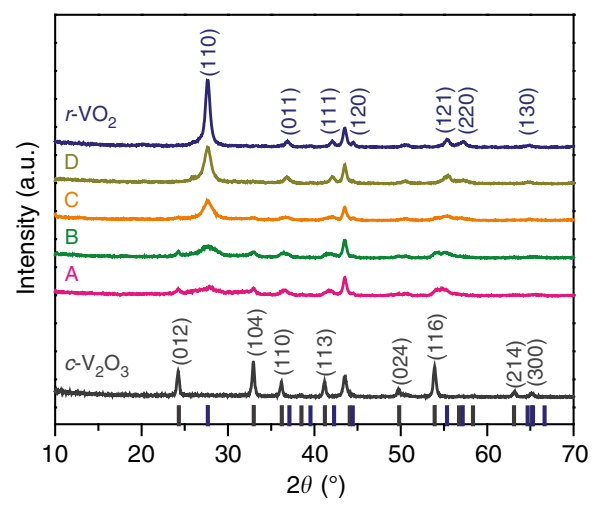

e

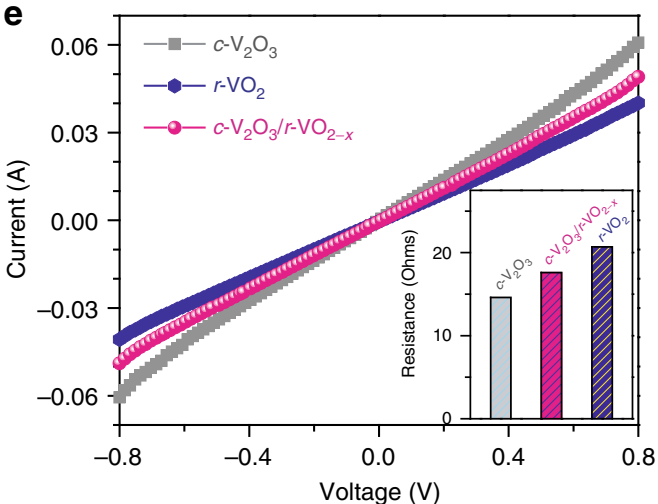

b
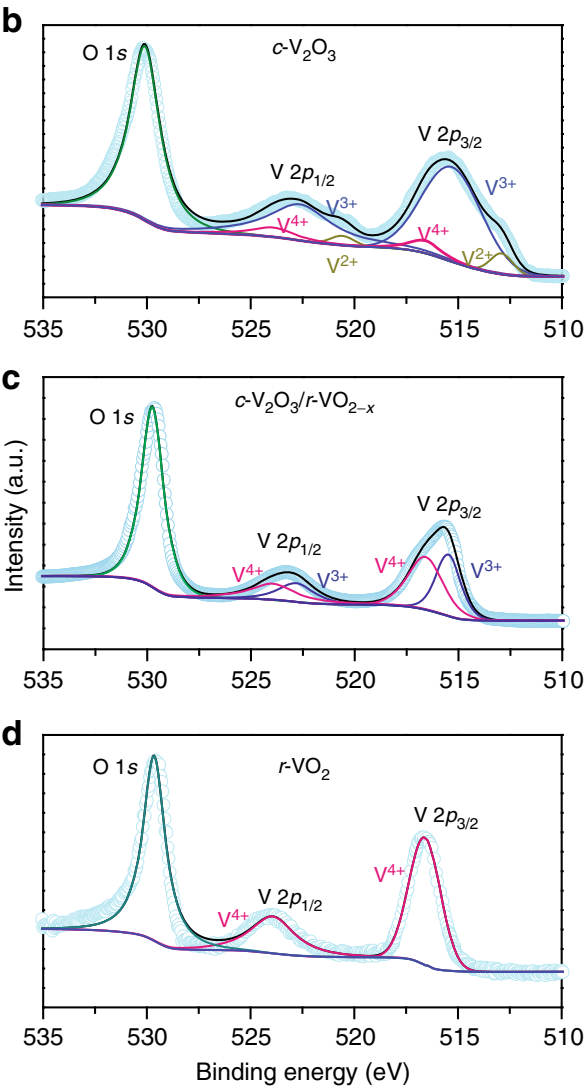

Fig. 3 Chemical analysis and electrical properties. a XRD patterns for $N P c-V_{2} O_{3}, r-V_{2}$ and $c-V_{2} O_{3} / r-V_{2-x}$ films, demonstrating the evolution of phase transformation via thermal oxidation of the corundum $c-\mathrm{V}_{2} \mathrm{O}_{3}$ at $300^{\circ} \mathrm{C}$ for 10 (A), 20 (B), 30 (C) and 60 min (D), respectively. The line patterns show reference cards 34-0187 and 44-0253 for the pristine $c-\mathrm{V}_{2} \mathrm{O}_{3}$ and $r-\mathrm{VO}_{2}$ according to JCPDS. b-d XPS spectra of O 1s, and $V 2 p$ for NP $c-\mathrm{V}_{2} \mathrm{O}_{3}$ (a), $c-$ $\mathrm{V}_{2} \mathrm{O}_{3} / r-\mathrm{VO}_{2-x}(\mathbf{b})$ and $r-\mathrm{VO}_{2}$ films (c), which are synthesized by thermal oxidation of the as-prepared $c-\mathrm{V}_{2} \mathrm{O}_{3}$ films for $0,10,90$ min at $300{ }^{\circ} \mathrm{C}$, respectively. e $I-V$ curves and the corresponding resistances (inset) of $N P c-V_{2} \mathrm{O}_{3}, c-V_{2} \mathrm{O}_{3} / r-\mathrm{VO}_{2-x}(x=0.22)$ and $r-\mathrm{VO}_{2}$ films

density because of the distinguished $r-\mathrm{VO}_{2-x}$ layer, in which the quasi-hexagonal tunnels facilitate the $\mathrm{Na}^{+}$intercalation/deintercalation in addition to the high conductivity of $\mathrm{V}-\mathrm{V}$ chains for the fast, reversible surface redox reactions for more energy storage/delivery. This is substantiated by the galvanostatic charge/ discharge measurements with a current density of $10.4 \mathrm{~A} \mathrm{~cm}^{-3}$, at which it takes much longer time to charge/discharge the NP $c$ $\mathrm{V}_{2} \mathrm{O}_{3} / r-\mathrm{VO}_{2-x}$ than the NP $c-\mathrm{V}_{2} \mathrm{O}_{3}$ and $r$ - $\mathrm{VO}_{2}$ (Supplementary Figure 13). Figure $4 \mathrm{~b}$ compares the gravimetric and volumetric capacitances of NP $c-\mathrm{V}_{2} \mathrm{O}_{3} / r-\mathrm{VO}_{2-x}(x=0.22)$ with the values of the NP $c-\mathrm{V}_{2} \mathrm{O}_{3}$ and $r-\mathrm{VO}_{2}$ at various scan rates (Supplementary Note 1). The NP $c-\mathrm{V}_{2} \mathrm{O}_{3} / r-\mathrm{VO}_{2-x}$ electrode achieves a gravimetric capacitance of as high as $\sim 1856 \mathrm{Fg}^{-1}$ (corresponding to the volumetric capacitance of $\sim 1933 \mathrm{~F} \mathrm{~cm}^{-3}$ ) at a scan rate of 5 $\mathrm{mV} \mathrm{s}^{-1}$. When the scan rate is increased to $1000 \mathrm{mV} \mathrm{s}^{-1}$, it still retains the capacitance of $760 \mathrm{~F} \mathrm{~g}^{-1}$ or $792 \mathrm{~F} \mathrm{~cm}^{-3}$, about 20 times the values of the NP $r-\mathrm{VO}_{2}\left(36 \mathrm{~F} \mathrm{~g}^{-1}\right.$ or $\left.37 \mathrm{~F} \mathrm{~cm}^{-3}\right)$. This exceptional rate performance enlists the $\mathrm{NP} c-\mathrm{V}_{2} \mathrm{O}_{3} / r-\mathrm{VO}_{2-x}$ electrode to outperform not only volumetrically but gravimetrically some of the best pseudocapacitive electrodes in a full rate range reported previously: such as nanotubular arrayed $\mathrm{RuO}_{2}{ }^{9}$, hydrogenated$\mathrm{TiO}_{2} / \mathrm{MnO}_{2}\left(\mathrm{H}-\mathrm{TiO}_{2} / \mathrm{MnO}_{2}\right)$ hybrid ${ }^{19}$, bare $\mathrm{MnO}_{2}{ }^{20}, \mathrm{Ti}_{3} \mathrm{C}_{2} \mathrm{~T}_{x}$ MXene clay ${ }^{36}, \mathrm{~N}$-doped mesoporous few-layer carbon (MFLC-N) 37 and nanostructured hexagonal $\mathrm{WO}_{3}{ }^{38}$. Even for the $\mathrm{NP} c$ $\mathrm{V}_{2} \mathrm{O}_{3} / r-\mathrm{VO}_{2-x}$ film electrode with thickness increasing to $7.8 \mu \mathrm{m}$, almost same pseudocapacitive behavior remains (Supplementary Figure 14).

To illustrate the unique charge/discharge kinetics, the anodic/ cathodic current $(i)$ is assumed to obey a power-law relationship of scan rate $(v)^{10,11,15,23}$, i.e., $i=a v^{b}$, with $a$ and $b$ being adjustable values. The $b$-value of 0.5 or 1 indicates that the current is a diffusion- or surface-controlled process, respectively. In a $\ln (i)-\ln (v)$ plot, the NP $c-\mathrm{V}_{2} \mathrm{O}_{3} / r-\mathrm{VO}_{2-x}(x=0.22)$ electrode possesses a $b$-value of 1 in the scan rates ranging from 5 to 100 $\mathrm{mV} \mathrm{s}^{-1}$, implying the surface-controlled kinetics in the discharging time $>8 \mathrm{~s}$. While for $v>100 \mathrm{mV} \mathrm{s}^{-2}$, the $b$-value decreases to 0.76 , which is due to the kinetic constraint of $\mathrm{Na}^{+}$diffusion in addition to ohmic contribution revealed by electrochemical impedance spectroscopy analysis in a frequency range from $100 \mathrm{kHz}$ to $10 \mathrm{mHz}$ (Supplementary Figure 15 and Supplementary Note 2$)^{39,40}$. This is in sharp contrast with the charge storage in pristine $\mathrm{NP} c-\mathrm{V}_{2} \mathrm{O}_{3}$ and $r-\mathrm{VO}_{2}$, which is dominated by a diffusion-controlled process in a full range of scan rates (Supplementary Figure $12 \mathrm{~d})^{10,11,15}$. Owing to the remarkably enhanced kinetics of $\mathrm{Na}^{+}$accessibility and electron transport, the interfacial charge transfer resistance $\left(R_{\mathrm{CT}}\right)$ and the Warburg resistance $\left(Z_{\mathrm{w}}\right)$ of the $\mathrm{NP} c-\mathrm{V}_{2} \mathrm{O}_{3} / r-\mathrm{VO}_{2-x}$ electrode are much lower than the values of the NP $c-\mathrm{V}_{2} \mathrm{O}_{3}$ and $r-\mathrm{VO}_{2}$ (Supplementary Figure $15 \mathrm{c}, \mathrm{d})$. Figure $4 \mathrm{c}$ shows the plot of normalized capacitance versus $v^{-1 / 2}$ for the NP $c-\mathrm{V}_{2} \mathrm{O}_{3} / r-\mathrm{VO}_{2-x}(x=0.22)$ electrode from 5 to $1000 \mathrm{mV} \mathrm{s}^{-1}$. Two distinct regions in $v<100$ $\mathrm{mV} \mathrm{s}^{-1}$ and $v>100 \mathrm{mV} \mathrm{s}^{-1}$ are exhibited, further validating the fact that the total specific capacitance $\left(C_{\mathrm{s}}\right)$ of $\mathrm{NP} c-\mathrm{V}_{2} \mathrm{O}_{3} / r-\mathrm{VO}_{2-x}$ arises from the diffusion-controlled intercalation pseudocapacitance (rate-dependent component, $\kappa_{2} v^{-1 / 2}$ ) coupled with the surface-controlled redox pseudocapacitance (rate-independent component, $\left.\kappa_{1}\right)^{10,11,15}$, i.e., $C_{\mathrm{s}}=\kappa_{1}+\kappa_{2} v^{-1 / 2}$. At scan rates below $100 \mathrm{mV} \mathrm{s}^{-1}$, the extrapolated intercept to $v^{-1 / 2}=0$ yields 

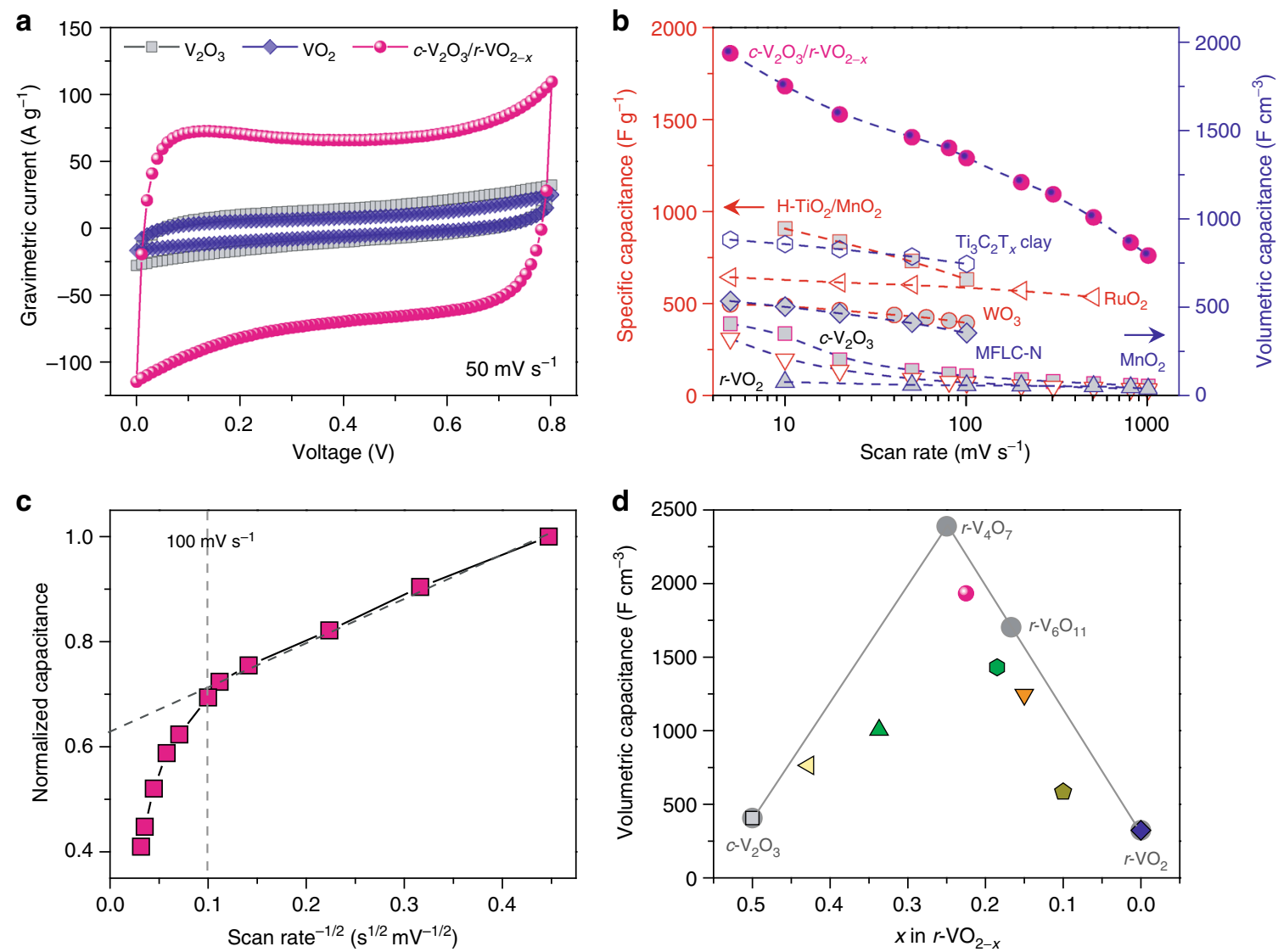

Fig. 4 Electrochemical characterization of electrodes in aqueous electrolyte. a Cyclic voltammetry (CV) curves of $\mathrm{NP}^{c}-\mathrm{V}_{2} \mathrm{O}_{3}, r-\mathrm{VO}_{2}$ and c- $\mathrm{V}_{2} \mathrm{O}_{3} / r-\mathrm{VO} \mathrm{O}_{2-x}$ $(x=0.22)$ electrodes in three-electrode configuration at a scan rate of $50 \mathrm{mV} \mathrm{s}^{-1}$ in $1 \mathrm{M} \mathrm{Na}_{2} \mathrm{SO}_{4}$. $\mathbf{b}$ Gravimetric and volumetric capacitances for NP $c^{-}$ $\mathrm{V}_{2} \mathrm{O}_{3}, r-\mathrm{VO}_{2}$ and $c-\mathrm{V}_{2} \mathrm{O}_{3} / r-\mathrm{VO}_{2-x}$ electrodes at various scan rates, comparing with the volumetric values previously reported for $\mathrm{Ti}_{3} \mathrm{C}_{2} \mathrm{~T}_{\mathrm{x}} \mathrm{MXene}$ clay ${ }^{36}, \mathrm{~N}-$ doped mesoporous few-layer carbon (MFLC-N) ${ }^{37}$ and bare $\mathrm{MnO}_{2}$ electrodes ${ }^{20}$, as well as the gravimetric values of mesoporous RuO ${ }_{2}{ }^{9}$, hydrogenated$\mathrm{TiO}_{2} / \mathrm{MnO}_{2}\left(\mathrm{H}-\mathrm{TiO}_{2} / \mathrm{MnO}_{2}\right)^{19}$ and nanostructured hexagonal $\mathrm{WO}_{3}{ }^{38}$. c Plot of normalized capacitance versus scan rate ${ }^{-1 / 2}$ for the separation of diffusion-controlled intercalation pseudocapacitance from surface-controlled redox pseudocapacitance in the scan rates from 5 to $1000 \mathrm{mV} \mathrm{s}^{-1}$. d Evolution of volumetric capacitances of $\mathrm{NP} c-\mathrm{V}_{2} \mathrm{O}_{3} / r-\mathrm{VO}_{2-x}$ electrodes at a scan rate of $5 \mathrm{mV} \mathrm{s}{ }^{-1}$ as a function of $x$. The gray solid circles and lines are the theoretically volumetric capacitances for $\mathrm{NP} c-\mathrm{V}_{2} \mathrm{O}_{3} / r-\mathrm{VO}_{2-x}$ based on the atomic structures with $x=0,0.167,0.25$ and 0.5 , which correspond to $r-\mathrm{VO}$, metastable $r-\mathrm{VO}_{2-x}$ and $c-\mathrm{V}_{2} \mathrm{O}_{3}$, respectively

the redox pseudocapacitance that just accounts for about two fifths of total capacitance. This indicates that the charge storage is mainly contributed by the $\mathrm{Na}^{+}$insertion/extraction, which behaves in a capacitive energy storage for the charge/discharge time of $8 \mathrm{~s}$ or longer. Whereas the intercalation pseudocapacitance is conventionally limited by solid-state diffusion in conventional $\mathrm{TMOs}^{10}, 11,15$, it improves significantly the energy-storage density without compromise of rate performance in the NP $c-\mathrm{V}_{2} \mathrm{O}_{3} / r-\mathrm{VO}_{2-x}$ electrodes because of the unique microstructure of $r-\mathrm{VO}_{2-x}$, which offers both redox and intercalation pseudocapacitance with similarly facile kinetics. The dominance of $\mathrm{Na}^{+}$intercalation/de-intercalation is further demonstrated by the fact that the NP $c-\mathrm{V}_{2} \mathrm{O}_{3} / r-\mathrm{VO}_{2-x}$ electrodes maintain similar pseudocapacitive behaviors and rate performance while their volumetric capacitances increase with the $x$ value, but are independent of the production amount of rutile phase in the CTR-phase transformation (Fig. 4d and Supplementary Figure 16). This is also verified by the general observation for the NP $c-\mathrm{V}_{2} \mathrm{O}_{3}$ decorated with few $r-\mathrm{VO}_{2-x}$ by shortening the thermal-oxidation time (Supplementary Figure 17), which exhibits slightly enhanced volumetric capacitance despite the negative deviation in the range of $x$ values far away from one fourth due to the contribution of the disordered distribution of quasi-hexagonal tunnels, i.e., the effect of configurational entropy
(Fig. 4d). Whereas vanadium oxides generally suffer from cycling instability, our NP $c-\mathrm{V}_{2} \mathrm{O}_{3} / r-\mathrm{VO}_{2-x}$ electrode shows exceptional durability in long-term galvanostatic charge/discharge cycles (Supplementary Figure 18), which are performed in a potential window of $0-0.8 \mathrm{~V}$ at a current density of $80 \mathrm{~A} \mathrm{~g}^{-1}$ in $1 \mathrm{M} \mathrm{Na}_{2} \mathrm{SO}_{4}$ aqueous electrolyte (inset of Supplementary Figure 18a). After 10,000 cycles, more than $90 \%$ capacitance still remained (Supplementary Figure 18a). XPS analysis demonstrates that the slight degradation of capacitance may result from the weeny change of surface valance state of $r-\mathrm{VO}_{2-x}$ layer $(x=0.23)$ relative to that of the as-prepared one $(x=0.22)$ (Supplementary Figure 18b), but not the dissolution of vanadium oxides which usually takes place in previously reported vanadium oxide electrodes (Supplementary Figure 18c) ${ }^{41,42}$

Electrochemical performance of devices. In view of the bipolar property of NP $c-\mathrm{V}_{2} \mathrm{O}_{3} / r-\mathrm{VO}_{2-x}$ electrode (Supplementary Figure 19), symmetric pseudocapacitors are assembled with two identical NP $c-\mathrm{V}_{2} \mathrm{O}_{3} / r$ - $\mathrm{VO}_{2-x}$ films as both cathode and anode, and one piece of cotton paper as a separator for evaluating the practical energy-storage performance. By virtue of the special bipolar properties of vanadium oxides, their voltage windows can be extended to $1.4 \mathrm{~V}$ from $0.8 \mathrm{~V}$ in $1 \mathrm{M} \mathrm{Na} \mathrm{NO}_{4}$ aqueous 

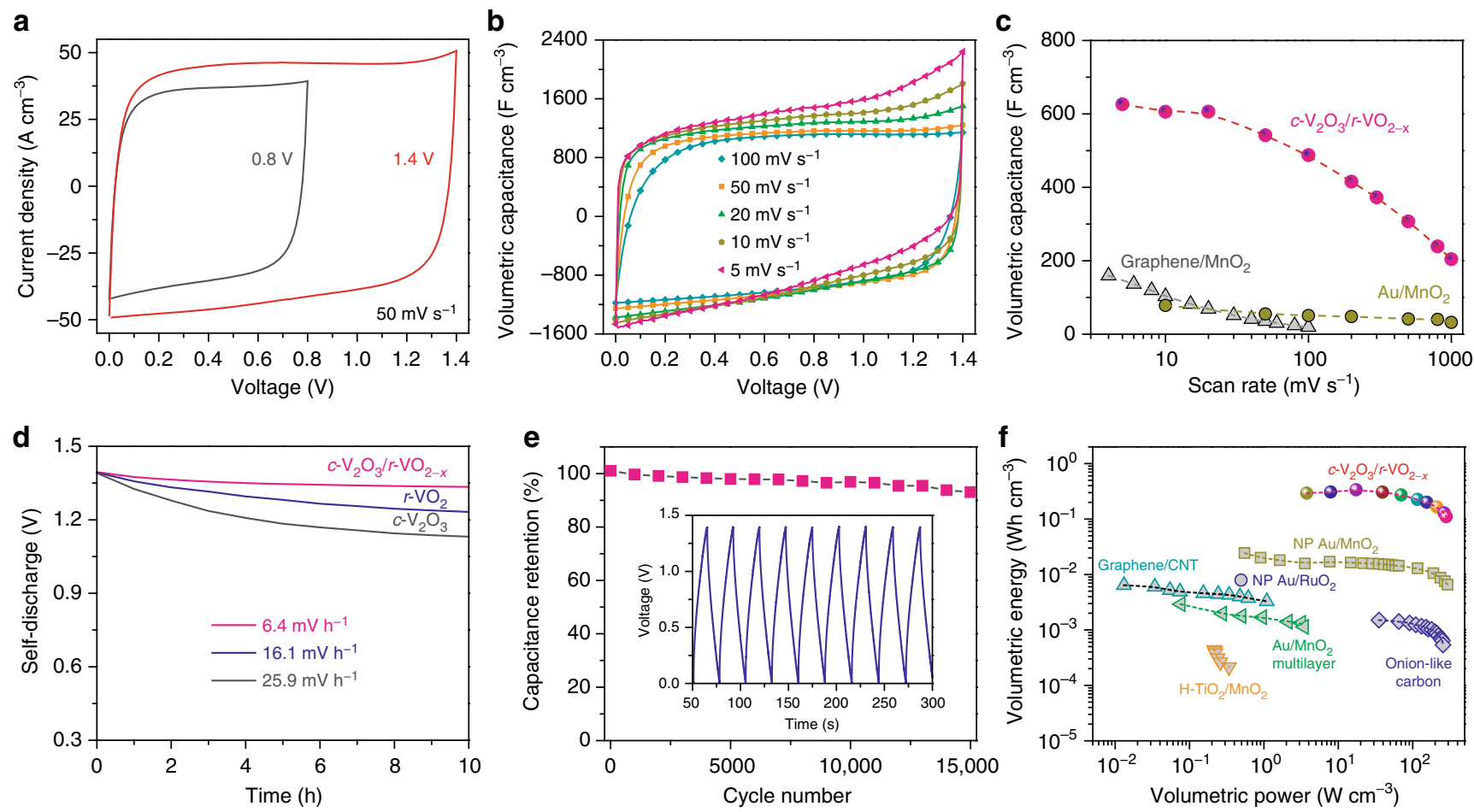

Fig. 5 Performance of aqueous symmetric pseudocapacitor devices in a wide voltage window. a CV curves for symmetric pseudocapacitors, with NP c$\mathrm{V}_{2} \mathrm{O}_{3} / r-\mathrm{VO}_{2-x}(x=0.22)$ as electrodes, in the voltage window extended from 0.8 to $1.4 \mathrm{~V}$ at a scan rate of $50 \mathrm{mV} \mathrm{s}^{-1}$ in $1 \mathrm{M} \mathrm{Na}_{2} \mathrm{SO}_{4}$ aqueous electrolyte. $\mathbf{b}$ $\mathrm{CV}$ profiles in a voltage window of $1.4 \mathrm{~V}$ for pseudocapacitors at different scan rates. $\mathbf{c}$ Volumetric capacitances of device of $\mathrm{NP} \mathrm{c}-\mathrm{V}_{2} \mathrm{O}_{3} / r-\mathrm{VO} \mathrm{O}_{2-x}(x=0.22)$ electrode at various scan rates, comparing with the volumetric values of previously reported supercapacitors based on graphene/MnO $\mathrm{O}_{2}$ hybrid electrodes and $\mathrm{Au} / \mathrm{MnO}_{2}$ multilayers. d Self-discharge performances for symmetric pseudocapacitors based on $\mathrm{NP} c-\mathrm{V}_{2} \mathrm{O}_{3} / r-\mathrm{VO}_{2-x} c-\mathrm{V}_{2} \mathrm{O}_{3}$ and $r-\mathrm{VO}_{2}$ electrodes. e Cycling stability performance for $\mathrm{NP} c-\mathrm{V}_{2} \mathrm{O}_{3} / r-\mathrm{VO}_{2-x}$-based pseudocapacitor in the voltage window of $1.4 \mathrm{~V}$. Inset: Galvanostatic cycling curves collected at $130 \mathrm{~A} \mathrm{~cm}^{-3}$ in $1 \mathrm{M} \mathrm{Na}_{2} \mathrm{SO}_{4}$ aqueous electrolyte. $\mathbf{f}$ Ragone plot of volumetric power versus volumetric energy for pseudocapacitors based on total volumetric of $\mathrm{NP} \mathrm{c}-\mathrm{V}_{2} \mathrm{O}_{3} / r-\mathrm{VO}_{2-x}$ in two electrodes, comparing with other electrochemical capacitors based on representative electrode materials such as onion-like carbon ${ }^{5}$ and graphene/CNT hybrid ${ }^{6}$, as well as $\mathrm{H}-\mathrm{TiO}_{2} / \mathrm{MnO}_{2}{ }^{19}, \mathrm{Au} / \mathrm{MnO}_{2}$ multilayers ${ }^{20}, \mathrm{NP} \mathrm{Au} / \mathrm{MnO} \mathrm{O}_{2}$ and $\mathrm{NP} \mathrm{Au}^{\mathrm{RuO}}{ }_{2}^{44}$

electrolyte when securing against the occurrence of oxygen evolution reaction. As shown in Fig. 5a, the CV curve of symmetric $\mathrm{NP} c-\mathrm{V}_{2} \mathrm{O}_{3} / r-\mathrm{VO}_{2-x}(x=0.22)$ pseudocapacitor at a scan rate of $50 \mathrm{mV} \mathrm{s}^{-1}$ displays a perfect rectangular and symmetrical shape within the wide voltage of $1.4 \mathrm{~V}$ because of the identical pseudocapacitance and charge/discharge kinetic properties of two electrodes. Furthermore, their facile redox reaction and cation intercalation kinetics not only realizes high-density charge storage but also leads to exceptional high-rate performance of the symmetric pseudocapacitor over a wide range from 5 to $1000 \mathrm{mV} \mathrm{s}^{-1}$. Therein, the $\mathrm{Na}^{+}$intercalation is demonstrated by Raman spectra of the charged/discharged NP $c-\mathrm{V}_{2} \mathrm{O}_{3} / r-\mathrm{VO}_{2-x}$ films (Supplementary Figure 20). There appears new characteristic Raman peaks at the frequencies of 962 and $224 \mathrm{~cm}^{-1}$, in addition to the shoulders 420 and $162 \mathrm{~cm}^{-1}$, for the charged $\mathrm{NP} c-\mathrm{V}_{2} \mathrm{O}_{3} / r-\mathrm{VO}_{2-x}$ film due to the $\mathrm{Na}^{+}$intercalation ${ }^{43}$. Although the pseudocapacitor starts to exhibit resistive behavior at $200 \mathrm{mV} \mathrm{s}^{-1}$, the symmetric $\mathrm{CV}$ retains quasi-rectangular shape even at the scan rate increasing to $1000 \mathrm{mV} \mathrm{s}^{-1}$ (Fig. 5b and Supplementary Figure 21). Figure $5 \mathrm{c}$ shows the volumetric capacitances of pseudocapacitor device as a function of scan rate. At $5 \mathrm{mV} \mathrm{s}^{-1}$, the NP $c-\mathrm{V}_{2} \mathrm{O}_{3} / r$ $\mathrm{VO}_{2-x}$ electrode reaches the highest volumetric capacitance of $\sim 626 \mathrm{~F} \mathrm{~cm}^{-3}$. As the scan rate is increased by 20 times (from 5 to $\left.100 \mathrm{mV} \mathrm{s}^{-1}\right)$, the capacitance maintains $\sim 77 \%\left(\sim 487 \mathrm{~F} \mathrm{~cm}^{-3}\right)$, much higher than supercapacitors based on $\mathrm{Au} / \mathrm{MnO}_{2}$ multilayers $^{20}$ or graphene $/ \mathrm{MnO}_{2}$ hybrid electrodes ${ }^{44}$. Meanwhile, the $\mathrm{Na}^{+}$cation storage in the tunnels with $E_{\text {int }}=\sim-0.8 \mathrm{eV}$ essentially depresses the self-discharge of electrochemical cells. A voltage drop of $\sim 0.006 \mathrm{~V} \mathrm{~h}^{-1}$ in the symmetric $\mathrm{NP} c-\mathrm{V}_{2} \mathrm{O}_{3} / r-\mathrm{VO}_{2-x^{-}}$ based pseudocapacitor is much lower than the ones with NP $r$ $\mathrm{VO}_{2}\left(\sim 0.016 \mathrm{~V} \mathrm{~h}^{-1}\right)$ and $c-\mathrm{V}_{2} \mathrm{O}_{3}\left(\sim 0.026 \mathrm{~V} \mathrm{~h}^{-1}\right)$ electrodes, on which the charge storage is realized by surface redox reactions (Fig. 5d). The cycling life of the $\mathrm{NP} c-\mathrm{V}_{2} \mathrm{O}_{3} / r-\mathrm{VO}_{2-x}$ device is tested by galvanostatic charge/discharge at a current density of $130 \mathrm{~A} \mathrm{~cm}^{-3}$ (inset of Fig. 5e). The significant capacitance retention, about $93 \%$ of the initial capacitance after 15,000 cycles (Fig. 5e), indicates its impressive long-term durability in the voltage window between 0 and $1.4 \mathrm{~V}$.

The volumetric and gravimetric power and energy densities of the symmetric pseudocapacitor are calculated according to the volume and mass of $\mathrm{NP} c-\mathrm{V}_{2} \mathrm{O}_{3} / r-\mathrm{VO}_{2-x}$ in two electrodes, respectively. Their maxima reach $\sim 330 \mathrm{mWh} \mathrm{cm}^{-3}$ and $\sim 320$ $\mathrm{mWh} \mathrm{g}^{-1}$, very superior to the values reported in the double-layer supercapacitors based on onion-like carbon ${ }^{5}$ or graphene/carbon nanotube hybrid ${ }^{6}$, and the pseudocapacitors with electrode materials including pseudocapacitive MFLC- ${ }^{37}$, and conventional TMOs even with carbon nets or fibers, and nanoporous metal skeletons serving as conductive pathways (Fig. $5 \mathrm{f}$ and Supplementary Figure 22) $9,19,45$. When delivered at the maximum power of NP $\mathrm{Au} / \mathrm{MnO}_{2}$ pseudocapacitor and onionlike carbon supercapacitor $\left(\sim 280 \mathrm{~W} \mathrm{~cm}^{-3}\right)^{5}$, our pseudocapacitor still has a volumetric energy density of $\sim 110 \mathrm{mWh} \mathrm{cm}^{-3}$, which is more than one and two orders of magnitude higher than their volumetric energies, respectively. The Ragone plot shown in Supplementary Figure 23 compares the volumetric power and energy based on the whole pseudocapacitor volume with those of commercially available energy-storage devices, where the volumes of two current collectors and one piece of paper separator are also 
included in the calculation. The NP $c-\mathrm{V}_{2} \mathrm{O}_{3} / r-\mathrm{VO}_{2-x}$-based pseudocapacitor stores charge with density of $\sim 13 \mathrm{mWh} \mathrm{cm}^{-3}$, which is slightly higher than that of $4 \mathrm{~V} / 500 \mu \mathrm{Ah}$ thin-film lithium batteries 5 , 6 . Furthermore, it can deliver high levels of electrical power, comparable to carbon-based supercapacitors ${ }^{6}$. These properties certify the unique capability of $\mathrm{NP} c-\mathrm{V}_{2} \mathrm{O}_{3} / r$ $\mathrm{VO}_{2-x}$-based pseudocapacitors to realize high-density energy storage/delivery at high power or fast charge/discharge rates, which makes them potentially competitive against batteries, such as lead-acid batteries and thin-film lithium batteries, for many high-power applications.

\section{Discussion}

We have demonstrated 3D hierarchical NP $c-\mathrm{V}_{2} \mathrm{O}_{3} / r-\mathrm{VO}_{2-x}$ films, which are fabricated by a facilely thermal-oxidationactuated CTR-phase transformation of NP $c-\mathrm{V}_{2} \mathrm{O}_{3}$ precursor, as bipolar electrode materials for symmetric wide voltage window pseudocapacitors in aqueous electrolyte. The phase transformation enlists the in situ grown $r$ - $\mathrm{VO}_{2-x}$ layer to be composed of highly $\mathrm{Na}^{+}$accessible hexagonal oxygen-deficiency tunnels sandwiched between highly conductive $r-\mathrm{VO}_{2}$ slabs, which essentially boosts the kinetics of redox and intercalation pseudocapacitance. Associated with electrode architecture of 3D bicontinuous and multimodal nanoporosity, the gravimetric and volumetric pseudocapacitances of the NP $c-\mathrm{V}_{2} \mathrm{O}_{3} / r-\mathrm{VO}_{2-x}$ electrodes are enhanced relative to the nanoporous pristine $r-\mathrm{VO}_{2}$ by a factor of 5-21 in a wide range of scan rates from 5 to $1000 \mathrm{mV}$ $\mathrm{s}^{-1}$. This renders their symmetric pseudocapacitor to reach a maximum volumetric energy of $\sim 330 \mathrm{mWh} \mathrm{cm}^{-3}(\sim 13 \mathrm{mWh}$ $\mathrm{cm}^{-3}$ based on the whole volume of device, beyond that of $4 \mathrm{~V} /$ $500 \mu \mathrm{Ah}$ thin-film lithium batteries) while delivering power densities similar to those of carbon-based supercapacitors. Furthermore, in a wide voltage window of $1.4 \mathrm{~V}$, the pseudocapacitor exhibits exceptional low self-discharge behavior and outstanding long-term durability.

\section{Methods}

Fabrication of nanoporous isomeric vanadium oxide electrodes. All 3D multimodal nanoporous film electrodes were fabricated by using polystyrene (PS) opal templates with size of $0.4 \mathrm{~cm} \times 0.4 \mathrm{~cm} \times 2 \mu \mathrm{m}$, which were assembled by $\mathrm{NH}_{4}{ }^{+}$terminated PS nanospheres with diameter of $\sim 450 \mathrm{~nm}$ on stainless steel substrates via evaporative deposition at $80^{\circ} \mathrm{C}$. An electrodeposition technique was employed to incorporate vanadium oxide into the PS opal templates on a three-electrode setup, in which a $\mathrm{Pt}$ foil and an $\mathrm{Ag} / \mathrm{AgCl}$ electrode were used as the counter electrode and reference electrode. Following the electrodeposition at $1.5 \mathrm{~V}$ (vs Ag/ $\mathrm{AgCl}$ ) for $80 \mathrm{~s}$ in an electrolyte containing $1 \mathrm{M} \mathrm{VOSO}_{4}$ and $1 \mathrm{mM} \mathrm{H}_{2} \mathrm{SO}_{4}, \mathrm{NP} c$ $\mathrm{V}_{2} \mathrm{O}_{3}$ films with loading mass of $\sim 20$ and $130 \mu \mathrm{g}$ were obtained by calcining the mixture films at $450{ }^{\circ} \mathrm{C}$ in $\mathrm{H}_{2} / \mathrm{Ar}$ air, which enables selective removal of PS nanospheres and thermal reduction of vanadium oxide. Employing the as-prepared $\mathrm{NP} c-\mathrm{V}_{2} \mathrm{O}_{3}$ films as the precursor scaffolds, $\mathrm{NP} c-\mathrm{V}_{2} \mathrm{O}_{3} / r$ - $\mathrm{VO}_{2-x}$ films were prepared by thermal oxidation at $300{ }^{\circ} \mathrm{C}$ in a tube furnace sealed with ambient atmosphere, wherein the $r-\mathrm{VO}_{2-x}$ layers were tuned by controlling the heat treatment time ranging from 2 to $60 \mathrm{~min}$. The $\mathrm{NP} r-\mathrm{VO}_{2}$ films were achieved by extending the heat treatment time to $90 \mathrm{~min}$.

Structure characterizations. The microstructures of $\mathrm{NP} c-\mathrm{V}_{2} \mathrm{O}_{3}, c-\mathrm{V}_{2} \mathrm{O}_{3} / r-\mathrm{VO}_{2-x}$ and $r-\mathrm{VO}_{2}$ were investigated using a field-emission scanning microscope (JEOL JSM-6700F, $15 \mathrm{keV}$ ) and a field-emission transmission electron microscope (JEOL JEM-2100F, $200 \mathrm{keV}$ ). HR-STEM characterization was performed on a fieldemission transition electron microscope (JEM-ARM200F, $200 \mathrm{kV}$ ) equipped with double spherical aberration correctors for the condenser lens and objective lens. The chemical composition was characterized by X-ray photoelectron spectroscopy on Thermo ECSALAB 250 with an $\mathrm{Al}$ anode. Binding energies were calibrated using containment carbon $(\mathrm{C} 1 s=284.6 \mathrm{eV})$. Nitrogen adsorption/desorption isotherms at $77 \mathrm{~K}$ were measured on a micromeritics ASAP 2020 system to evaluate the specific surface area by the BET method, as well as the pore volume and the pore size by the Barrett-Joyner-Halenda (BJH) method. X-ray diffraction measurements were performed on a D/max2500pc diffractometer using $\mathrm{Cu} \mathrm{Ka}$ radiation. Raman spectra were collected using a micro-Raman spectrometer (Renishaw) with a laser of $532 \mathrm{~nm}$ wavelength at $0.2 \mathrm{~mW}$. Temperature dependence of resistivity was collected on Hall Effect measurement system (HMS-5000).
Electrochemical measurements. Electrochemical properties of single electrode were characterized in a classic three-electrode setup (Iviumstat electrochemical analyser, Ivium Technology) using $\mathrm{Pt}$ foil as counter electrode, $\mathrm{Ag} / \mathrm{AgCl}$ electrode as reference electrode and $1 \mathrm{M} \mathrm{Na}_{2} \mathrm{SO}_{4}$ as aqueous electrolyte. Electrochemical performances of pseudocapacitor devices were measured in a two-electrode configuration. Cyclic voltammetry and galvanostatic charge/discharge were performed in potential windows from 0 to $0.8 \mathrm{~V},-0.8$ to $0.8 \mathrm{~V}$ and from 0 to $1.4 \mathrm{~V}$ at various scan rates and current densities, respectively. Self-discharge measurements were performed by charging pseudocapacitors based on $\mathrm{NP} c-\mathrm{V}_{2} \mathrm{O}_{3}, c-\mathrm{V}_{2} \mathrm{O}_{3} / r-\mathrm{VO}_{2-\mathrm{x}}$ and $r-\mathrm{VO}_{2}$ electrodes to $1.4 \mathrm{~V}$ at $0.2 \mathrm{~mA}$, followed by open-circuit potential selfdischarging for $50 \mathrm{~h}$.

DFT simulation. All DFT computations were performed using the CASTEP code with ultrasoft pseudopotentials. The exchange-correlation effects were described by the generalized gradient approximation with the Perdew-Burke-Ernzerhof functional (PBE). A $400 \mathrm{eV}$ cutoff was employed for the plane-wave basis set and the $k$ point separations in Brillouin zone were set as $0.04 \AA^{-1}$. The geometry optimizations were carried out until energy, maximum force and displacement were less than $10^{-5} \mathrm{eV} /$ atom, $0.03 \mathrm{eV}^{-1}$ and $0.001 \AA$, respectively. The bulk phases of $\mathrm{VO}_{2}$ ${ }_{-x}(x=0.167$ and 0.250$)$ were simulated by optimizing both lattice parameters and atomic positions of $r-\mathrm{VO}_{2}$, where an $\mathrm{O}$ atom was removed in the $3 \times 1 \times 1$ and $2 \times$ $1 \times 1$ supercells, respectively. Interface models consisting of $r-\mathrm{VO}_{2}(011)$ slabs $(13.66 \times 5.37 \AA)$ and $c-\mathrm{V}_{2} \mathrm{O}_{3}(012)$ slabs $(14.85 \times 5.47 \AA)$ was established to simulate the coherent interface structures of $c-\mathrm{V}_{2} \mathrm{O}_{3} / r-\mathrm{VO}_{2}$ and $c-\mathrm{V}_{2} \mathrm{O}_{3} / r-\mathrm{VO}_{2-x}(x=0.167)$ with ordered or disordered oxygen vacancies after adding $20 \AA$-thick vacuum along the direction perpendicular to the interface. The intercalation energies $\left(E_{\text {int }}\right)$ of a $\mathrm{Na}$ atom into the bulk $r-\mathrm{VO}_{2}, r-\mathrm{VO}_{2-x}(x=0.167$ and 0.250$)$ were calculated according to the equation: $E_{\mathrm{int}}=E_{\mathrm{VO}+\mathrm{Na}}-\left(E_{\mathrm{VO}}+1 / 2 E_{\mathrm{Na}}\right)$, where $E_{\mathrm{VO}+\mathrm{Na}}, E_{\mathrm{VO}}$ and $E_{\mathrm{Na}}$ are the total energies of vanadium oxides with one adsorbed $\mathrm{Na}$ atom, vanadium oxides and $\mathrm{Na}$ bulk, respectively. The energy barriers for $\mathrm{Na}$ diffusion in $\mathrm{VO}_{2}$ and $\mathrm{VO}_{2-x}$ were determined by optimizing several images between the initial and final structures along each path.

Data availability. All relevant data are available from the corresponding authors (xylang@jlu.edu.cn and jiangq@jlu.edu.cn) upon request.

Received: 22 May 2017 Accepted: 7 March 2018

Published online: 10 April 2018

\section{References}

1. Simon, P. \& Gogotsi, Y. Materials for electrochemical capacitors. Nat. Mater. 7, 845-854 (2008)

2. Conway, B. E. Electrochemical Supercapacitors: Scientific Fundamentals and Technological Applications (Kluwer, New York, 1999).

3. Chmiola, J. et al. Anomalous increase in carbon capacitance at pore sizes less than 1 nanometer. Science 313, 1760-1763 (2006).

4. Lee, S. W., Gallant, B. M., Byon, H. R., Hammond, P. T. \& Shao-Horn, Y. Nanostructured carbon-based electrodes: bridging the gap between thin-film lithium-ion batteries and electrochemical capacitors. Energy Environ. Sci. 4, 1972-1985 (2011).

5. Pech, D. et al. Ultrahigh-power micrometer-sized supercapacitors based on onion-like carbon. Nat. Nanotechnol. 5, 651-654 (2011).

6. $\mathrm{Yu}, \mathrm{D}$. et al. Scalable synthesis of hierarchically structured carbon nanotubegraphene fibers for capacitive energy storage. Nat. Nanotechnol. 9, 555-562 (2014).

7. Toupin, M., Brousse, T. \& Bélanger, D. Charge storage mechanism of $\mathrm{MnO}_{2}$ electrode used in aqueous electrochemical capacitor. Chem. Mater. 16, 3184-3190 (2004).

8. Lang, X. Y., Hirata, A., Fujita, T. \& Chen, M. W. Nanoporous metal/oxide hybrid electrodes for electrochemical supercapacitors. Nat. Nanotechnol. 6, 232-236 (2011).

9. Hu, C. C., Chang, K. H., Lin, M. C. \& Wu, Y. T. Design and tailoring of the nanotubular arrayed architecture of hydrous $\mathrm{RuO}_{2}$ for next generation supercapacitors. Nano. Lett. 6, 2690-2695 (2006).

10. Lindström, H. et al. $\mathrm{Li}^{+}$ion insertion in $\mathrm{TiO}_{2}$ (anatase). 2. Voltammetry on nanoporous films. J. Phys. Chem. B 101, 7717-7722 (1997).

11. Augustyn, V. et al. High-rate electrochemical energy storage through $\mathrm{Li}^{+}$ intercalation pseudocapacitance. Nat. Mater. 12, 518-522 (2013).

12. Liu, P., Zhu, K., Gao, Y., Luo, H. \& Lu, L. Recent progress in the applications of vanadium-based oxides on energy storage: from low-dimensional nanomaterials synthesis to $3 \mathrm{D}$ micro/nano-structures and free-standing electrodes fabrication. Adv. Energy Mater. 7, 1700547 (2017).

13. Yue, Y. \& Liang, H. Micro- and nano-structured vanadium pentoxide $\left(\mathrm{V}_{2} \mathrm{O}_{5}\right)$ for electrodes of lithium-ion batteries. Adv. Energy Mater. 7, 1602545 (2017). 
14. Conway, B. E., Birss, V. \& Wojtowicz, J. The role and utilization of pseudocapacitance for energy storage by supercapacitors. J. Power Sources 66, 1-14 (1997).

15. Augustyn, V., Simon, P. \& Dunn, B. Pseudocapacitive oxide materials for high-rate electrochemical energy storage. Energy Environ. Sci. 7, 1597-1614 (2014).

16. Salanne, M. et al. Efficient storage mechanisms for building better supercapacitors. Nat. Energy 1, 16070 (2016).

17. Fang, Q. L., Evans, D. A., Roberson, S. L. \& Zheng, J. P. Ruthenium oxide film electrodes prepared at low temperatures for electrochemical capacitors. J. Electrochem. Soc. 148, A833-A837 (2001).

18. Mondal, S. K. \& Munichandraiah, N. Anodic deposition of porous $\mathrm{RuO}_{2}$ on stainless steel for supercapacitor studies at high current densities. J. Power Sources 175, 657-663 (2008).

19. Lu, X. et al. H-TiO ${ }_{2} @ \mathrm{MnO}_{2} / / \mathrm{H}-\mathrm{TiO}_{2} @ \mathrm{C}$ core-shell nanowires for high performance and flexible asymmetric supercapacitors. Adv. Mater. 25, 267-272 (2013).

20. Si, W. et al. On chip, all solid-state and flexible micro-supercapacitors with high performance based on $\mathrm{MnO}_{\mathrm{x}} / \mathrm{Au}$ multilayers. Energy Environ. Sci. 6 , 3218-3223 (2013).

21. Ghodbane, O., Pascal, J. L. \& Favier, F. Microstructural effects on chargestorage properties in $\mathrm{MnO}_{2}$-based electrochemical supercapacitors. ACS Appl. Mater. Interfaces 1, 1130-1139 (2009).

22. Yuan, Y. et al. The influence of large cations on the electrochemical properties of tunnel-structured metal oxides. Nat. Commun. 7, 13374 (2016).

23. Brezesinski, T., Wang, J., Tolbert, S. H. \& Dunn, B. Ordered mesoporous $\alpha-$ $\mathrm{MoO}_{3}$ with iso-oriented nanocrystalline walls for thin-film pseudocapacitors. Nat. Mater. 9, 146-151 (2010).

24. Lukatskaya, M. R., Dunn, B. \& Gogotsi, Y. Multidimensional materials and device architectures for future hybrid energy storage. Nat. Commun. 7, 12647 (2016).

25. Imada, M., Fujimori, A. \& Tokura, Y. Metal-insulator transitions. Rev. Mod. Phys. 70, 1039-1263 (1998).

26. Jeong, J. et al. Suppression of metal-insulator transition in $\mathrm{VO}_{2}$ by electric field-induced oxygen vacancy formation. Science 339, 1402-1405 (2013).

27. Wu, C., Feng, F. \& Xie, Y. Design of vanadium oxide structures with controllable electrical properties for energy applications. Chem. Soc. Rev. 42, 5157-5183 (2013).

28. Kang, K., Meng, Y. S., Bréger, J., Grey, C. P. \& Ceder, G. Electrodes with high power and high capacity for rechargeable lithium batteries. Science 311, 977-980 (2006).

29. Koudriachova, M. V., Harrison, N. M. \& de Leeuw, S. W. Density-functional simulations of lithium intercalation in rutile. Phys. Rev. B 65, 235423 (2002).

30. Liu, M., Su, B., Tang, Y., Jiang, X. \& Yu, A. Recent advances in nanostructured vanadium oxides and composites for energy conversion. Adv. Energy Mater. 7, 1700885 (2017).

31. Tompsett, D. A., Parker, S. C., Bruce, P. \& Islam, M. S. Nanostructuring of $\beta$ $\mathrm{MnO}_{2}$ : the important role of surface to bulk ion migration. Chem. Mater. 25, 536-541 (2013).

32. Xia, X. et al. $\mathrm{VO}_{2}$ nanoflake arrays for supercapacitor and $\mathrm{Li}$-ion battery electrodes: performance enhancement by hydrogen molybdenum bronze as an efficient shell material. Mater. Horiz. 2, 237-244 (2015).

33. Katzke, H. \& Schlögl, R. Mechanism of the morphotropic transformation between the rutile and corundum structural types. Acta Cryst. B59, 456-462 (2003).

34. Tominaka, S., Tsujimoto, Y., Matsushita, Y. \& Yamaura, K. Synthesis of nanostructured reduced titanium oxide: crystal structure transformation maintaining nanomorphology. Angew. Chem. Int. Ed. 50, 7418-7421 (2011).

35. Silversmit, G., Depla, D., Poelman, H., Marin, G. B. \& De Gryse, R. Determination of the V2p XPS binding energies for different vanadium oxidation states $\left(\mathrm{V}^{5+}\right.$ to $\left.\mathrm{V}^{0+}\right)$. J. Electron Spectrosc. Relat. Phenom. 135, 167-175 (2004).

36. Ghidiu, M., Lukatskaya, M. R., Zhao, M. Q., Gogotsi, Y. \& Barsoum, M. W. Conductive two-dimensional titanium carbide clay with high volumetric capacitance. Nature 516, 78-81 (2014).

37. Lin, T. et al. Nitrogen-doped mesoporous carbon of extraordinary capacitance for electrochemical energy storage. Science 350, 1508-1513 (2015).
38. Chen, $\mathrm{Z}$. et al. Hierarchical nanostructured $\mathrm{WO}_{3}$ with biomimetic proton channels and mixed ionic-electronic conductivity for electrochemical energy storage. Nano Lett. 15, 6802-6808 (2015).

39. Di Fabio, A., Giorgi, A., Mastragostino, M. \& Soavi, F. Carbon-poly(3methylthiophene) hybrid supercapacitors. J. Electrochem. Soc. 148, A845-A850 (2001).

40. Gamby, J., Taberna, P. L., Simon, P., Fauvarque, J. F. \& Chesneau, M. Studies and characterizations of various activated carbons used for carbon/carbon supercapacitors. J. Power Sources 101, 109-116 (2001).

41. Perera, S. D. et al. Vanadium oxide nanowire-carbon nanobute binder-free flexible electrodes for supercapacitors. Adv. Energy Mater. 1, 936-945 (2011).

42. Wei, D. et al. A nanostructured electrochromic supercapacitor. Nano Lett. 12, 1857-1862 (2012)

43. Muller-Bouvet, D. et al. Electrochemically formed $\alpha-\mathrm{NaV}_{2} \mathrm{O}_{5}$ : a new sodium interaction compound. Electrochim. Acta 176, 586-593 (2015).

44. El-Kady, M. F. et al. Engineering three-dimensional hybrid supercapacitors and microsupercapacitors for high-performance integrated energy storage. Proc. Natl. Acad. Sci. USA 112, 4233-4238 (2015)

45. Ferris, A., Garbarino, S., Guay, D. \& Pech, D. 3D $\mathrm{RuO}_{2}$ microsupercapacitors with remarkable areal energy. Adv. Mater. 27, 6625-6629 (2015).

\section{Acknowledgements}

This work was supported by the National Natural Science Foundation of China (No. 51631004, 51422103), Top-notch Young Talent Program of China (W02070051), Chang Jiang Scholar Program of China (Q2016064), the Program for JLU Science and Technology Innovative Research Team (JLUSTIRT, 2017TD-09), the Fundamental Research Funds for the Central Universities and the Program for Innovative Research Team (in Science and Technology) in University of Jilin Province.

\section{Author contributions}

X.-Y.L. and Q.J. conceived and designed the experiments. B.-T.L., X.-Y.L., L.G. and Z.W. carried out the fabrication of materials and performed the electrochemical and microstructural characterizations. X.-M.S. and Q.J. performed the DFT calculations. X.-Y.L., Q. J. and B.-T.L. wrote the paper, and all authors discussed the results and commented on the manuscript.

\section{Additional information}

Supplementary Information accompanies this paper at https://doi.org/10.1038/s41467 018-03700-3.

Competing interests: The authors declare no competing interests.

Reprints and permission information is available online at http://npg.nature.com/ reprintsandpermissions/

Publisher's note: Springer Nature remains neutral with regard to jurisdictional claims in published maps and institutional affiliations.

Open Access This article is licensed under a Creative Commons Attribution 4.0 International License, which permits use, sharing, adaptation, distribution and reproduction in any medium or format, as long as you give appropriate credit to the original author(s) and the source, provide a link to the Creative Commons license, and indicate if changes were made. The images or other third party material in this article are included in the article's Creative Commons license, unless indicated otherwise in a credit line to the material. If material is not included in the article's Creative Commons license and your intended use is not permitted by statutory regulation or exceeds the permitted use, you will need to obtain permission directly from the copyright holder. To view a copy of this license, visit http://creativecommons.org/ licenses/by/4.0/

(c) The Author(s) 2018 